\title{
Merleau-Ponty e Mantovani: diálogos de forma e conteúdo
}

Fausto Sanches. E-mail: faustosanches@yahoo.com.br Mestrando em Filosofia pela Universidade Federal de Uberlândia.

Resumo: Através de leituras analíticas e comparativas entre as obras de MerleauPonty e de Mantovani, tivemos por objetivo apresentarmos uma interpretação da poesia do segundo, sustentada em noções cuja clareza é dependente da filosofia de Merleau-Ponty. Esperamos, com isto, estabelecermos os termos dessa aproximação subentendida. O que avançamos, como conclusão, é que Mantovani é a expressão poética da definição filosófica da expressão, segundo Merleau-Ponty.

Palavras-chave: Merleau-Ponty; Mantovani; símbolo.

Abstract: Through to analytics reading in comparison between the works of the Merleau-Ponty and of the Mantovani, we had to purposes to presente un interpretation the poetry of the second, supported in notions whose intelligibility is dependent the philosophy of the Merleau-Ponty. We have the hope of to establish the terms of that approach. Concluding, we to say beforehand which Mantovani is the poetic expression to philosophical definition the expression according to Merleau-Ponty.

Key-words: Merleau-Ponty; Mantovani; symbol.

O que aqui se pretende, através de um procedimento teórico, analítico e interpretativo, estrutura-se em duas fases distintas, simultâneas e complementares. Primeiro, pretendemos propor uma análise pela qual apresentamos a nossa definição do sentido das noções centrais, correlatas e que se determinam reciprocamente, presentes em A Luta de Jacó e do Anjo, quais sejam, "paradoxo", "desencontro" e "símbolo", sob os aspectos etimológicos, filosóficos e estéticos. O esclarecimento destas noções-chaves de leitura e interpretação consistiu na explicitação da complexidade intrínseca às mesmas, de modo que, talvez, não tenhamos alcançado bom êxito nesta tarefa. Inseparável desta e respeitando a indicação de Mantovani que admitiu a influência do filósofo francês Maurice Merleau-Ponty, pretendemos ter apresentado indícios iniciais para ulteriores aprofundamentos que vejam a pertinência em se analisar em que consistiu esta influência, e mensurá-la no que diz respeito à definição do sentido daquelas noções. O que poderá ser observado, neste sentido, é que a poesia de Mantovani parece ser o exemplo do modo como Merleau-Ponty condiciona a expressividade lingüística e entende ser a essência da linguagem e do fazer poético, literário, artístico, e mesmo filosófico.

Ora, em que consiste a condição de "símbolo" e qual a sua importância para diferenciarmos "coisa" e "obra"? O símbolo é precisamente o afastamento e o esquecimento do aspecto coisa. "O substantivo 'símbolo' provém do verbo 'symballo' que significa reunir, juntar. O símbolo que define e caracteriza a arte indica que a obra possui algo mais e que se reveste do sagrado e do inefável" (Paviani, 1973, p. 21; segundo grifo é nosso). Ao atravessar a coisa rumo a uma profundidade, o símbolo é um caminho de re-união, de unidade e de estarmos juntos a. Por sua vez, em termos filosóficos, o paradoxo é o questionamento da aparência e o esforço analítico-crítico de 
superá-la pondo em relação idéias contrárias ou contraditórias. De origem grega, paradoxo significa "contrário à opinião comum, bizarro, inconcebível, extraordinário". Trata-se de um procedimento de pôr-se contrário à evidência imediata proveniente das contradições e conflitos próprios do aparente. "O paradoxo contém, apesar da aparência, uma verdade que se procura sustentar" (Folscheid e Wunenburger, 1997, p. 367). Esta verdade que está então depois da aparência e do imediato, depois dos aspectos coisais meramente visíveis, objetivos e positivos. Esta verdade está na ausência, é preciso escavar ausências para encontrá-la. Esta verdade não apenas está, portanto, no não visível, no não objetivo, mas, ela é, ela mesma, o negativo e, assim sendo, ela possui uma natureza metafísica e uma religiosidade cósmica. E, apenas o símbolo enquanto acesso a algo mais, ao sagrado e ao inefável, permite-nos nos relacionarmos e dizermos o negativo, a ausência, o verdadeiro, a essência.

"A luta e a poesia acontecem no desencontro, antes de tudo, interiorizado no homem como caminho" (Mantovani, 2008, p. 09). Para o poeta, o desencontro é elo e é caminho catártico de interiorização. O poeta - ser desencontrado - faz do desencontro um caminho para o seu próprio ser, para si mesmo. Nestes termos, o que o poeta escreve no desencontro é a aproximação e a proximidade a si mesmo. 0 poeta, nascendo e vivendo a dor e a angústia característica do "desencontro de mim e do eu" mostra em sua fala que o homem é assim constituído, que é um ser cindido que pode ser outro que ele mesmo e cuja reconciliação só acontece depois. O homem é, simultaneamente, Jacó e o Anjo, o eu e o outro, palavra e silêncio, corpo e alma, lugar e não-lugar. Em sua singularidade autêntica, embora particular, ele traz em si mesmo a universalidade. Esta é o que no homem permanece esquecida e velada. O homem, em sua existência, deve lembrar-se e desvelar a sua essência, a sua universalidade, aquilo que lhe é mais próprio. E isto acontecerá, bem como o poeta nascerá do homem que se transcendeu através de uma auto-renúncia, quando o eu morrer como eu em seu outro ao propor-se não dizer, mas ouvir o silêncio e expressar o que está em silêncio, sufocado pelas palavras. E o poeta terá nascido, enfim, quando o homem se sentir sem-lugar, deslocado, quando ele adentrar e estiver num espaço que não é local em sentido estrito, mas sim, que pode ser, esta falta de lugar, um sentimento.

Eis o que Mantovani, retornando aos gregos, entende ser, mais do que antes, a tarefa do poeta hegeliano-existencialista, a saber: responsabilizando-se pelo seu ser, o poeta é a negação do homem, ele morre-se como homem, ele enfrenta, suporta e permanece na dor e no desespero para ultrapassar sua finitude e seus limites humanos, para oferecer aos homens a lembrança, para mostrar-lhes que devem perceber e desvelar o desapercebido. O poeta é Jacó, o homem ou o particular incompleto, inquieto, conflituoso, angustiado e infeliz que se lança ao encontro do universal (do Anjo) que simboliza a sua morte, e suporta a violência deste encontro para alcançar, oferecer e mostrar aos homens o que é por completo, a paz e a quietude que estão no originário. Esta é a cisão, o desencontro, o paradoxo interior ao homem. Cisão e desencontro entre o finito (Jacó, o homem, o aquém) e o infinito (o Anjo, o divino, o além), e paradoxo de ser uma consciência "rachada" que transita 
entre dois mundos. Nestes termos, se tomamos o primeiro dos significados gregos de ánthropos, que é “o humano por oposição ao divino" (Chauí, 1994, p. 343), é possível concebermos uma antropologia na poesia de Mantovani, na medida em que a sua poesia 1) nasce desta oposição e 2) se faz caminho da sua superação, ou seja, de uma reconciliação. Ilustramos o primeiro aspecto com o poema "Depois do sétimo dia da Criação":

Na lágrima da luz, encontramos as coisas diluídas em filigranas de poemas.

\section{E com o poema "O Encontro do Poeta e da Poesia":}

Em minhas olheiras, o desencontro de Jacó e do Anjo.

A poesia é apreensão de filigranas nas coisas; ela nasce como procura e o poeta é um inquieto buscador. $O$ que o poeta espera é o momento de um encontro cujo ponto de partida é o desencontro.

$E$, o segundo aspecto, a poesia como busca de reconciliação, ilustramos com versos do poema "A Legítima Busca: o inefável e o paradoxo":

\footnotetext{
Que Deus sois vós que se escondeis e se mostrais em uma palavra impronunciável dentro de cada palavra de todas as línguas?

(...)

Essa palavra que perdi e que agora busco, e que, por vezes, creio reencontrá-la nalgum poema.
}

Há dentro da palavra um silêncio fundamental que o poeta busca dizer por meio da fala poética. Ele busca dizer a negação de toda palavra. Para tanto, o poeta deve sair da linguagem, pois a poesia não é linguagem, assim como, a obra (a literatura) não está na linguagem meramente dada e comunicativa. A poesia, a literatura e a obra advêm num depois que é princípio, começo, antes, ou, conforme Merleau-Ponty, quando atravessamos as palavras, o dito, as letras no papel, e adentramos no querer-dizer de uma ausência de signo originária (2002, p. 32-37). Para o filósofo francês, passar despercebida, apagar-se em benefício do sentido, trazer à tona o querer-dizer no avesso do dito, não é sinônimo de uma fraqueza congênita da linguagem, bem ao contrário, "é exatamente a virtude da linguagem" (idem, p. 32). O que significa lutar para "doar voz e trazer à expressão a ausência, o avesso, o silêncio em que se cliva o inefável, a sobre-realidade" (Mantovani, 2008, p. 9). Tal virtude é o fundamento de uma linguagem considerada em sua essência, é aquilo que lhe é mais próprio - propriedade com a qual trabalha o escritor -, "é ela que nos lança ao que ela significa". A linguagem é caminho, caminho que nos conduz para além dele mesmo quando, "em minhas olheiras" há "o desencontro da linguagem e da linguagem", inaugural e sempre presente em a Poesia da Ausência (Mantovani, 2008, p. 34). A linguagem se transcende e se descentra para dizer o que lhe excede, o que ela não possui, dissimulando-se "a 
nossos olhos por sua operação mesma" (Merleau-Ponty, 2002, p. 32), para dar-nos acesso, "para além das palavras, ao próprio pensamento do autor" (ibidem). Este é o seu triunfo, o triunfo da expressão. E isto significa, para Merleau-Ponty, que a linguagem não é, por si mesma, espontaneamente, obra. Para ela se tornar obra, a linguagem deve sair de si, estar descentrada e perder o seu equilíbrio, isto é, enfrentar a ameaça da não-linguagem e da ausência de sentido, quando ela está sem centro, para então se reordenar ou vir a si enquanto obra ${ }^{[i]}$. E este seu tornar-se obra só compreendo a posteriori, ou seja, não é minha leitura que cria a obra, mas sim, sou conduzido pela linguagem tornando-se obra ou pela obra que se cumpre através da linguagem, para além da linguagem, quando esta já não é mais apenas falada, mas, originária, viva e falante. Há, portanto, duas linguagens, a adquirida e "a que se faz no momento da expressão, que vai justamente fazer-me passar dos signos ao sentido" (ibidem). Por conseguinte, "no momento da expressão", a linguagem deixa de ser falada e adquirida, e se torna falante e veicula-nos um sentido inédito, não sedimentado. A linguagem falante não é uma linguagem já feita, pronta e acabada, mas sim, uma linguagem que só se faz no momento da expressão. Um livro, uma obra, se se trata de criações autênticas, foram confeccionados com essa linguagem falante que passa e nos leva para além da linguagem, das letras e das páginas. É quando sou despossuído e, ao mesmo tempo, quando o livro toma posse de mim ao clivar-se para além da sua materialidade e impedir-me de encontrá-lo, gratuitamente e sem surpresas, em minhas mãos e sob os meus olhos.

A expressão sustenta o devir da linguagem e o devir do sentido ao ser o elo entre a linguagem falada e a linguagem falante. Primeiramente, é pela linguagem falada "o terreno já comum das significações adquiridas e disponíveis" (idem, p. 33) - que o autor se instala em meu mundo, lançando mão do sentido sedimentado dos signos sobre os quais concordamos. Mas, ele pretende, se ele conseguiu transformar a linguagem em obra, "atrair-me para mais além", isto é, deixar-me descentrado e despossuído, apresentando-me um sentido estranho e conduzindo-me para fora desse "terreno já comum". Estas condições ensejam uma pergunta: o que faz, onde está e como o autor vem a si, ou, o que é o mesmo, quando a linguagem deixa de ser linguagem e se torna obra, em suma, qual o momento de ocorrência da literatura, da poesia? O autor, a obra e a literatura fazem e se encontram em um desvio. O autor, imperceptivelmente, "desvia os signos de seu sentido ordinário". A literatura é este desvio. Este desvio é caminho para o sentido que transcende os signos, para o quererdizer depois do dito. Então, se ela não está na linguagem, no signo e no sentido, a literatura é a correlação, para além da sua objetividade lingüística, entre um sobre-

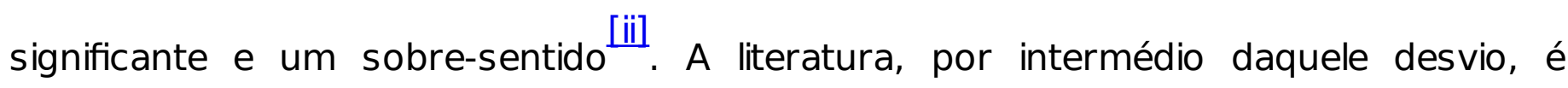
adentramento na ausência de linguagem, ela é ausência de signo como signo do que a despossuía e, por conseguinte, despossuía-nos também. Retornar e reabsorver a ausência de signo como signo é retornar a uma linguagem originária e explicitar o seu próprio fundamento: esta transcendência de si relacionando-se com a ausência, com o 
imprevisto, com o inusitado, enquanto retorno e explicitação das suas origens, ou seja, a expressão.

A linguagem verdadeiramente expressiva, que se auto-fundamenta em sua virtude própria de produzir o sentido, é aquela que retorna, explicita e retoma sua origem: o silêncio. Há literatura, ou a linguagem é expressiva, se ela respeita sua condição essencial, qual seja, trazer consigo, em seu interior, o silêncio originário, o silêncio falante, a ausência originária de signo. Eis o que faz o escritor se ele é verdadeiramente escritor. Antes de conviver com as palavras, ele escuta-as, abandonase a elas, ele convive com o silêncio das palavras, e ele está no intervalo entre o mesmo (a linguagem instituída ou falada) e o outro (a linguagem instituinte, expressiva, viva ou falante), enfim, na linguagem diferenciando-se de si mesma. O escritor, a literatura ou uma obra são relevos ou diferenças em relação à linguagem, em relação ao comum e ao já conhecido. O que identifica e revela o estilo de um escritor é o modo de ele fazer o desvio ou a diferença que ele apresenta enquanto modo de apresentar-se. A criação, o vir a si da obra para além da linguagem, está na diferenciação, que é, portanto, uma instância interior e originária de deiscência do sentido inédito. Essa diferenciação proveniente daquele caminho de desvio é a saída do que sei para o saber do que ainda não sei. Assim, por exemplo, "sei, antes de ler Stendhal, o que é um patife, e posso portanto compreender o que ele quer dizer quando escreve que o fiscal Rossi é um patife" (Merleau-Ponty, 2002, p. 33-4; grifo nosso). Mas, quando sou conduzido do patife para o fiscal Rossi, não estou mais no conhecido, em meu mundo, em minhas palavras, em minha moral, e daqui eu fui retirado por uma "torção secreta" do sentido ordinário, que é, a bem da verdade, aquela diferenciação pela qual fui modificado e reconheço o mundo novo, o sobre-sentido, a moral de Stendhal.

À medida que as intersecções se multiplicam e que mais flechas apontam para esse lugar de pensamento onde jamais estive antes, onde talvez, sem Stendhal, jamais teria ido, à medida que as ocasiões nas quais Stendhal as emprega indicam sempre mais imperiosamente o sentido novo que ele lhes dá, aproximo-me cada vez mais dele até finalmente ler suas palavras na intenção mesma com que as escreveu (Merleau-Ponty, 2002, p. 34; grifos nossos).

É Stendhal, pelo êxito imperioso do seu exprimir-se (êxito de sair da linguagem para o outro da linguagem), que me conduz para "onde jamais estive antes", porque é onde Stendhal está e se pôs através de um racional e árduo esforço [iii]. E deste onde ele nos chama, isto é, apresenta-nos um mundo novo pleno de sentido a ser explorado, a ser compreendido. Este onde é antes, é origem. Esse chamado é para o que nos é mais próprio. Eis o que faz o escritor que, percorrendo sem guia o caminho desviante da linguagem para a obra, apresenta-nos e nos oferece o que nos é mais próprio, porém, não de um modo gratuito. Esse chamado do próprio que o escritor escuta no silêncio das palavras é, antes, uma exigência, pois o que nos é mais próprio é do que em nossas ações mais naturais (por exemplo, pensar e falar) mais nos afastamos e menos percebemos. É preciso resistir e romper esta nociva naturalidade do pensamento e da fala para dizermos e desvelarmos o desapercebido que nos 
chama. A poesia é uma escuta desse chamado do que permanece, na Luta e no esforço do poeta, indizível em sua Totalidade.

O poeta não escreve com alguma esperança, pelo contrário, ele corajosamente escreve com o desespero de não saber se suas palavras não passarão de um grito evanescente. O poeta não oferece nenhuma esperança gratuita e ilusória, mas, afastando-se da aparência do inessencial sedimentado, ele oferece em seu gesto autêntico de auto-renúncia e de afirmação da sua existência, o desespero, a dor e o sofrimento constitutivos dos homens que, sufocados pelo inapropriado inautêntico, deixam de perceber. Para ultrapassar a ilusão sedimentada - o véu do desapercebido o poeta escreve com a não-linguagem, com a negação da linguagem - a poesia - e, fazendo-o, ele está próximo da origem, do lugar apropriado do ser. Sem desespero, dor e sofrimento, a poesia não é caminho de aproximação de onde podemos ser propriamente. O poeta busca encontrar e oferecer um lugar apropriado para sermos, e a poesia é onde o ser tem lugar, onde podemos experimentá-lo.

A fala poética deve ser originária, criativa e falante; ela deve ser mostração do não-manifesto, do oculto, do esquecido, do inefável. Essa fala, para ser boa para os homens, para ter lugar entre eles e para ser o lugar em que eles se encontram e estão próximos a si mesmos, deve ter a eficácia de ultrapassar o esquecimento. Ora, houve uma palavra com tal eficácia, qual seja, alétheia. A sua eficácia é a de uma palavra que anuncia, que é anunciação que sustenta, tal como um cajado, "misto de luz, de verdade e de caminho" (Mantovani, 2008, p. 32). Essa palavra inspirada era capaz de dizer o que estava depois da aparência sensível e imediata das coisas. Através dessa palavra inspirada, capaz de dizê-lo, se manifestava o invisível, o que estava velado, o negativo. Através da palavra alétheia, eram "capazes de ver o invisível: o passado, o futuro e o reino dos mortos" (Chauí, 1994, p. 35). Esse trazer à manifestação o oculto ou desocultá-lo é fazer. O Mestre da Verdade, através da sua fala, faz acontecer, sua fala traz em si um acontecimento. Neste momento primordial, "não há distância entre falar e fazer, palavra e ação" (Idem, 1994, p. 36), fala e fazer co-incidem ${ }^{[i v]}$. Sua palavra tem a eficácia e a força do acontecimento e o acontecimento que ela veicula em si é a manifestação da verdade enquanto o tornar visível o invisível. A palavra inspirada faz ver a verdade, porque, em grego, verdade "é uma palavra que se diz negativamente: alétheia" (Idem, 1994, p.35). Diz-se a verdade através do negativo. O negativo é signo da verdade, para encontrá-la devemos enfrentar e passar pela negação, devemos deixar o instante e a matéria presentes e adentrar no "reino dos mortos", o que significa que devemos - tal como fez epicamente Jacó - enfrentar nossa morte simbólica. Se Léthe quer dizer esquecimento, esquecido, Alétheia é não esquecimento, não esquecido, lembrado ${ }^{[\mathrm{V}]}$. Mestres desta palavra originária, sobretudo na Grécia arcaica, "o poeta, o adivinho e o rei-de-justiça são os que não esquecem e não deixam os homens esquecer. Capazes de ver o invisível ou o oculto (...), esses três personagens lembram por meio da palavra" (Chauí, 1994, 35). Agora podemos entender o que Mantovani disse na orelha do livro, preocupando-se em encontrar um 
lugar para o homem reconciliar-se consigo mesmo, com o outro e com o mundo:

O homem sem-lugar é aquele que perdeu a capacidade de falar (...). Dentro de uma palavra originária, autêntica e verdadeira (que os homens perderam e que os primeiros filósofos, ainda poetas, chamavam alétheia), o homem realiza-se e afirma o seu ser mais próprio. Eis a tarefa metafísico-religiosa do poeta: reencontrar, tal como um arqueólogo, a palavra desvelante que está sob a linguagem contemporânea (daí ser o subsolo o seu caminho) e, dizendo-a, mostrar e chamar aos homens para o que lhes é mais próprio. Em sua tarefa, o poeta é este que diz ao símbolo esquecido: 'Não te deixarei ir, se não me abençoares' (Gênesis 32: 26). E com ele luta até o romper do dia pousando na matéria (Texto orelha).

Em seu poema de abertura (que é, na verdade, uma abertura-caminho para o inacabado), Mantovani relata uma visita que é também uma origem. Trata-se da visita do Inefável e da origem da sua poesia como "um embate doloroso, religiosometafísico" (Mantovani, 2008, p. 09) para buscar expressá-lo. Depois desta visita, há um excesso constitutivo das coisas, há uma presença excessiva, e este excesso é a ausência que não é vazio ou não-ser. Eis seu relato:

\begin{abstract}
A luz deposita suavidade nas coisas, enchendo-as de profecias a serem decifradas; véu de luz - mística da matéria - pousando um Símbolo sobre um corpo grávido de Paradoxo.
\end{abstract}

A matéria não está meramente dada, isto é, ela não se reduz aos seus aspectos meramente visíveis e objetivos. Há nela certa indeterminação e inobjetivação que transcende e a estende para além da sua substância e do seu aspecto coisal, o que significa admitir e afirmar que a matéria é também seus aspectos não dados, subentendidos, ou o invisível. Em sentido próprio, aquilo que ela é está depois de si mesma; este paradoxo é o que lhe deixa-ser, e o que deixa-ser é o mais fundamental que se encontra sempre depois. Portanto, o paradoxo é caminho para o fundamento, para o que nos deixa-ser em sentido próprio. Neste sentido, onde se origina, o que sustenta e o que deve pintar o pintor quando ele se propõe realizar um retrato? Em uma palavra, o excesso. Quando ele atravessa os "objetos cheios de si mesmos" e capta o Devaneio da matéria, está inaugurada uma estética do simbólico, para a qual,

O retrato é uma viagem através da

des-figuração - o verdadeiro rosto

está depois da figura.

O retrato da des-figuração alcança o depois.

O excesso é o não-figurado, o sem peso, o hipermaterial depois das figuras visíveis que são os fenômenos, que são modos de aparecer do inaparente inesgotável ou do verdadeiro real. Eis porque podemos falar, segundo Mantovani, que o cotidiano pode não ser apenas o literal, mas ser também hiper-realista e colorido pela "percepção do sonho da realidade" (Mantovani, 2008, p. 29). O poeta é aquele que sabe que não caminha sobre a separação entre a matéria e o símbolo, é aquele que Luta contra a nossa tendência natural, inapropriada e alienante de separarmos a matéria e o paradoxo e, além disso, de percebermos apenas a matéria, enquanto que o paradoxo é 
o desapercebido. O paradoxo é o excesso que deve ser percebido, dito, pintado, mostrado. A questão, para Mantovani, é que submetidos cotidianamente ao inapropriado - que é o que nos afasta de nós mesmos, daquilo que somos esquecemos, naturalmente, daquela unidade originária entre o paradoxo e a matéria. Além disso, em termos poético-metafóricos, a "gravidez da matéria" (que a torna um símbolo grávido de uma suavidade mística e inefável), como toda gravidez, chega à luz, e, então, nasce o poeta, que é como uma mariposa que se suicida contra a luz. Pois, o "vir à luz" significa, justamente, a separação, a perda e o esquecimento daquela unidade originária. É então neste momento que começa o trabalho do poeta. Eis em que se radica e se legitima a sua Luta. Eis com o que ele se defronta em sua Luta: a Ausência de algo familiar que se tornou estranho, uma estranheza proveniente daquela separação, perda e esquecimento. Estranheza que se instaura quando não nos damos conta mais que, em sentido próprio e fundamentalmente, somos paradoxais. Os nossos paradoxos interiores são os nossos guia e caminho. Dizer isto é o que cabe ao poeta cujo trabalho consiste, nestes termos, em perceber o desapercebido, em dizer o paradoxo, em presentificar aos homens a Ausência, mostrar-lhes que o que lhes é mais próprio tornou-se-lhes estranho e chamá-los para o Ser.

A matéria, as coisas, os objetos, o corpo, o visível, estão grávidos de paradoxo, isto é, de invisível, de inefável e de caminho. Em outros termos, “é próprio do visível ter u $\mathrm{m}$ forro de invisível no sentido próprio, que ele torna presente como uma certa ausência" (Merleau-Ponty, 1975, p. 279; grifos nossos). E ainda neste sentido: "quando vejo um objeto, sinto sempre que ainda existe ser para além daquilo que atualmente vejo, não apenas ser visível mas ainda ser tangível ou apreensível pela audição, e não apenas ser sensível mas ainda uma profundidade do objeto que nenhuma antecipação sensorial esgotará" (Idem, 1945, p. 250; grifo nosso). Para, Merleau-Ponty, a experiência do Ser acontece já no irrefletido, trata-se de uma experiência perceptiva, antepredicativa e intersensorial. Merleau-Ponty nos ensina que alcançamos o excesso ou o avesso das coisas e do visível através do entrecruzamento cinestésico dos sentidos para além dos seus limites biológicos e objetivos quando, por exemplo, a visão se faz tato e o tato se faz visão ${ }^{[v i]}$. O Ser, o que espera e exige ser expresso, se esconde e se manifesta no entrecruzamento enquanto acesso à Totalidade. Ora, esta intersensorialidade está fortemente presente em Mantovani. Em que termos? O poeta se utiliza de pintores, de escultores e de músicos, e muitos dos títulos dos seus poemas são títulos de pinturas e de obras musicais, sugerindo-nos um acordo e uma harmonia estética e primordial entre os signos, as cores, a matéria e os sons. Eis como exemplifica-nos esta harmonia, o poema "O violinista" (2008, p. 36):

Dedos inconscientes de dor e de bruma tocam,

quando sonham, a luz e as cores,

o solene encontro do corpo e da alma.

E versos do poema dedicado a Eugène Delacroix, "A tela e a profecia" (2008, p. 45): 
o poeta é cor, pois,

no avesso da cor, uma ausência

inexprimível, uma solidão,

um além no fundo inalcançável

do pincel (...).

"O solene encontro do corpo e da alma" é a tradução, em outros termos, da relação e do encontro paradoxal do humano e do divino, da matéria e do sagrado, do sensível e do inteligível. Esse encontro que, em certo sentido, Merleau-Ponty também buscou afirmar e descrever, procurando restringir as pretensões do cartesianismo que nasceu, estruturou-se e se mantinha sobre uma renitente dicotomia ontológica, qual seja, a da res cogitans e da res extensa. A partir desta dicotomia teve início um culto filosófico da representação intelectual como afastamento e negação da inteligibilidade da existência exterior representada, e um culto científico ao objeto. No primeiro caso, o Ser tornou-se "ser representado", cuja existência fora da representação intelectual carecia de certeza. No segundo caso, também negado e esquecido, o Ser tornou-se objeto, um objeto cuja inteligibilidade era determinada matematicamente. $E$, em ambos os casos, o homem é uma consciência absoluta afastada do seu começo, uma reflexão que se arrebata a si mesma "e se recoloca em uma subjetividade invulnerável para aquém do ser e do tempo" (Merleau-Ponty, 1945, p. 05). É preciso recuperar a existência do homem, as suas vivências (erlebniss) no Mundo da Vida (Lebenswelt), onde ele pode realizar sua liberdade de ser. Nestes termos, "minha liberdade, o poder fundamental que tenho de ser o sujeito de todas as minhas experiências, não é distinta de minha inserção no mundo. Para mim é um destino ser livre..." (Idem, 1945, p. 482). E este destino se cumprirá se eu me reconhecer como um ser-no-mundo, se eu me reconhecer inserido ou pertencente a um onde-em-que apropriado para eu estar próximo a mim mesmo, reconciliado, a um onde-em-que eu receba a Visita. Trata-se, não somente, de inserir o homem nos espaços (casas, escolas, instituições, praças, ruas, etc.), mas, sobretudo, de humanizá-los ou de torná-los apropriados para o homem, isto é, de dar-lhes espaços para que eles sejam ou existam em sentido próprio, doando-lhes um lar ou fazendo com que se sintam em casa. E o lar do ser é, fundamentalmente, a linguagem, diria Heidegger. Dar um lar ao homem é, antes de tudo, dar-lhe voz, é escutá-lo.

O que há e é necessário expressar é inesgotável e não se restringe à atualidade positiva. Para fazê-lo é preciso aprofundar-se, porque isto que espera e exige a nossa expressão é constituído, intrinsecamente, por um fundo de ausência, por uma negatividade que atapeta. Eis a épica tarefa do poeta: dizer o negativo, encontrar a criação na negação. Logo, em sua luta, tarefa e busca, a poesia é caminho. Mas caminho para onde? De antemão, tenhamos também presente que aquele que busca espera encontrar algo, espera um encontro. Então este caminho deve ser apropriado para um encontro que, por sua vez, pressupõe aproximação e proximidade.

Para que a poesia não seja afastamento de onde devemos encontrar e estarmos próximos do que buscamos tão forçosamente, ela será ultrapassamento, ela nos fará ver o inaparente que está ali nas coisas sustentando o aparecer delas, pois, 
conforme Mantovani, "desde a visita-gênese há alguma realidade no Depois". E isto significa o rompimento da separação entre a facticidade e a essência, entre o sensível e o inteligível, entre o signo e a significação. Assim, o que precisamos encontrar e do que precisamos estar próximos está-aí, encarnado ${ }^{[v i i]}$ em uma expressão sem tempo “materializando o imponderável" que engravida de luz o barro ${ }^{[\text {viii] }}$. o barro possui a inteligibilidade estético-simbólica, dentro dele há uma forma. O depois é dentro.

Em conclusão, expomos o que alcançamos por ora e as nossas impressões e dificuldades a este respeito. Sob a influência da filosofia existencialista de MerleauPonty, com acentos do Hegel de 1807, o poeta parte e acentua a tragédia da existência humana. Temeroso dos seus paradoxos, o homem não se dá conta da sua irreconciliação consigo mesmo e, nas suas ilusões que o sustentam, ele não consegue mais dizer suas dores e seus sofrimentos, ele não consegue mais exprimir o negativo. Daí Mantovani encontra em Merleau-Ponty uma fecunda análise da linguagem literária que the subsidia teoricamente para ele fundamentar o seu fazer poético e a poesia como fazer. A nossa conclusão mais significativa é também a mais polêmica e, com certeza, ela não se esgota aqui, qual seja: ao menos em seus dois primeiros livros, a leitura da poesia de Mantovani, se realizada separadamente do fundo filosófico que sua poesia admite e reclama, avançará pouco, em que pese a compreensão, pois, para o filósofo, a escrita e a leitura se dão no não-signo. Para alcançá-lo, é preciso abrir e morar dentro da linguagem. Analogamente, o poeta escreve com e no ante-símbolo, dimensão em que (Mantovani, 2008, p. 64):

A palavra é uma janela sem onde,
parada em tempo algum,
enquanto não se conseguir abri-la.

Neste sentido, nossa conclusão é mais uma recomendação: é oportuno, para um outro momento, analisar a natureza desta relação entre poesia e filosofia, questionando-se se a poesia de Mantovani teria algum tipo de autonomia e validade ou incontornável dependência em relação à influência que ele admitiu sofrer e absorver.

\section{Referências Bibliográficas:}

CHAUÍ, M. Introdução à história da filosofia. Vol. I. São Paulo: Brasiliense, 1994.

FOLSCHEID, D.; WUNENBURGER, J.-J. Metodologia Filosófica. São Paulo: Martins Fontes, 1997.

MANTOVANI, H. J. A Luta de Jacó com o Anjo: A Poesia da Ausência. São Paulo: Scortecci, 2008.

- Arqueologia da criação em Merleau-Ponty: plástica da des-figuração. In:

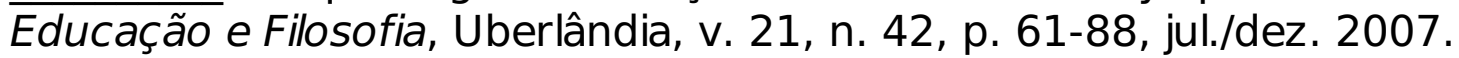

. Sobre-escritos. Rio de Janeiro: Câmara Brasileira de Jovens Escritores, 2006. MERLEAU-PONTY, M. A Prosa do Mundo. São Paulo: Cosac e Naify, 2002.

. Phénoménologie de la perception. Paris: Gallimard, 1945.

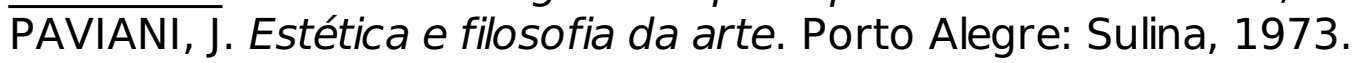


[i] É explícita a semelhança com as palavras de Mantovani que prefaciaram o seu livro Sobre-escritos: “... estamos falando de uma des-figuração semântica da linguagem que toca, temerosamente, 0 nãosentido, mas que deste momento de debilidade necessária, emerge enriquecida de um sentido novo e recriado, o sobre-sentido. A autêntica criação emerge do enfrentamento e da passagem pelo não-sentido, quando estamos, perigosamente, depois da linguagem e numa inquietante ausência de referenciais e de sentido, quando a linguagem des-figurada ainda não tomou plena posse de si ou veio a ser sobreescritos" (2006, p. 14; grifos do autor).

[ii]

Eis uma afirmação emblemática de Mantovani: “É essa linguagem depois da linguagem, criativa, que visamos, pois ela nos dá acesso e nos permite dizer os paradoxos - a realidade depois da realidade, a ausência metafísica que não é vazio ou negação, mas a sobre-realidade presente nas ruas, nas casas, nos rostos, nos passos, nos gestos, na fala, no pensamento, enfim, no essencialmente humano" (2006, p. 15; grifo do autor).

[iii] Esforço de ser caminho que conduz para um depois inefável em que os leitores, para verdadeiramente lerem, devem se encontrar. Neste sentido, diz-nos Mantovani: “É necessário que vocês estejam depois do entendimento e depois da linguagem. Se conseguimos conduzi-los para ali, se nos encontramos ali, então criamos, e podemos pensar e dizer o que antes não sabíamos nem pensar e nem dizer, o que antes nos era impensado e silêncio" (2006, p. 14; grifos do autor).

[iv]

O poeta lamenta que a contemporaneidade seja marcada, entre outros aspectos, pela perda desta palavra. A linguagem contemporânea perdeu a eficácia de fazer acontecer. Nestes termos, para Mantovani, a tarefa metafísico-religiosa do poeta consiste em "reencontrar, tal como um arqueólogo, a palavra desvelante que está sob a linguagem contemporânea (daí ser o subsolo o seu caminho) e, dizendo-a, mostrar e chamar aos homens para o que lhes é mais próprio. Em sua tarefa, o poeta é este que diz ao símbolo esquecido: 'não te deixarei ir, se não me abençoares (Gênesis 32:26). E com ele luta até o romper do dia pousando na matéria" (texto orelha).

[v]

Alétheia "é uma vidência e uma evidência, na qual a própria realidade se revela, se mostra ou se manifesta a quem conhece (...) e alethés, o verdadeiro, significa: o não esquecido, o não-escondido,..." (Chauí, 1994, p. 342).

[vi]

Além disto, a junção e confusão desses elementos - não mais fechados e restritos em suas aplicabilidades e dimensões próprias, mas, abertos e tomados em relação - tem por fim desfigurar e alargar a linguagem empírica, objetiva e inexpressiva. Este gesto inaugura o acesso a uma fala originária, expressiva, e capaz de dizer ou de tornar manifesto, eficazmente, o paradoxo, o ser por inteiro, o nosso ser mais próprio.

[vii] Argumento extraído do poema “Tela sem no: A Encarnação de Cristo", p. 13.

[viii]

Cf. o poema "Luz e lama: o homem-girassol", p. 19. 